\title{
COMPETÊNCIAS GERENCIAIS DE EMPREENDEDORES DE STARTUPS DE BELO HORIZONTE (MG)
}

\section{MANAGERIAL COMPETENCES OF STARTUPS ENTREPRENEURS OF BELO HORIZONTE (MG)}

\author{
Ana Paula Costa Oliveira \\ Universidade Federal de Minas Gerais - Mestre em Administração \\ Nova Lima, MG, Brasil \\ Email: anapaulacostaoliveira@hotmail.com \\ Victor Natanael Schwetter Silveira \\ Professor do CEPEAD / FACE / Universidade Federal de Minas Gerais \\ Belo Horizonte, MG, Brasil \\ Email: victornss@face.ufmg.br
}

\section{RESUMO}

O objetivo geral do estudo foi analisar como se configuram as competências gerenciais, ideais e reais, dos empreendedores de startups de Belo Horizonte (MG), segundo suas percepções, baseando-se no modelo de Quinn et al. (2003). Neste estudo teórico-empírico, de campo, de abordagem qualitativa e descritiva, os dados foram coletados por meio de questionários e entrevistas semiestruturadas, submetidas à análise de conteúdo, conforme Bardin (2008). Como resultado, no aspecto ideal, ganharam destaque os papéis de diretor, facilitador, monitor e inovador. Já no aspecto real, os sujeitos mencionaram os papéis de diretor, inovador, mentor e monitor, com a incidência do papel de facilitador. Conclui-se que, embora exista uma aproximação entre as competências ideais e reais, os empreendedores ainda devem desenvolver as competências associadas aos papéis de diretor e de facilitador, e, para o cumprimento dos oito papéis de Quinn et al. (2003), necessita-se ainda do desenvolvimento dos papéis de negociador e produtor.

Palavras-chave: Competências Gerenciais. Startups. Empreendedores. Gestores, Gestão de Pessoas.

\section{ABSTRACT}

The general objective of the study was to analyze the managerial competences, ideal and real, of entrepreneurs of startups of Belo Horizonte (MG), in their own perception, based on the Quinn et al. (2003) model. In this field-based theoretical-empirical study, with a qualitative and descriptive approach, the data were collected through questionnaires and semistructured interviews, submitted to content analysis, according to Bardin (2008). As a result, in the ideal aspect, the roles of director, facilitator, monitor and innovator were highlighted. Already in the real aspect, the subjects mentioned the roles of director, innovator, mentor and monitor, with the incidence of the role of facilitator. As conclusion, although there is an approximation between the ideal and real competences, the entrepreneurs still have to develop the competences associated to the roles of director and facilitator and, to fulfill the eight roles of Quinn et al. (2003), the role of negotiator and producer is still needed.

Keywords: Managerial Competence. Startups. Entrepreneurs. Managers, Human Resource Management.

Data de submissão: 3 de julho de 2018.

Data de aprovação: 16 de julho de 2019. 


\section{INTRODUÇÃO}

A dinâmica do mercado tem sido impactada pelas alterações tecnológicas, econômicas e sociais que vêm ocorrendo nos últimos anos, pressionando as empresas a conquistar o desenvolvimento de novos mercados, a criar diferenciais capazes de trazer vantagens competitivas e a gerar novos produtos e serviços. Nesse contexto, as mudanças nas configurações do mercado têm aberto espaços de negócios para organizações capazes de inovar, aplicar novas tecnologias e produzir produtos e serviços inéditos. Assim, a inovação, compreendida como elemento de destaque no desenvolvimento econômico e na expansão dos negócios no capitalismo moderno, é considerada como a base das estratégias de sucesso das organizações contemporâneas (SCHUMPETER, 1988).

Como consequência, este cenário de competitividade e busca contínua por inovação estimulou o surgimento de organizações conhecidas como startups, empresas que buscam suprir novas demandas de mercado e do consumidor, que atuam na criação de um novo modelo de negócio considerado inovador e que devem ser repetíveis e escaláveis (FIGUEIRA et al., 2017).

Diante disso, segundo Moreira et al. (2017), por estarem em um ambiente de incerteza e risco, demanda-se dos empreendedores das startups comportamentos e práticas que possibilitem superar os desafios, gerir e agir de forma ousada e inovadora. Além disso, segundo Arruda et al. (2014), a capacidade de adaptação e gestão desses sujeitos diante das mudanças de cenário está ligada à sobrevivência da organização. Portanto, verifica-se que o(s) ator(es) que empreendem e exercem a função gerencial dentro das startups influenciam diretamente no desempenho e na sobrevivência dessas instituições.

Observa-se, portanto, que os empreendedores de startups que atuam em cargos gerenciais devem possuir e desenvolver certas competências gerenciais, a fim de promover a eficácia do negócio, assim como apoiar e sustentar as capacidades organizacionais. Conforme afirmam Aziz et al. (2005), identificar as competências gerenciais possibilita contribuir para a atuação desses sujeitos, minimizando o conflito de papéis e a ambiguidade característica da função gerencial.

Outra questão relevante refere-se à lacuna existente entre as competências ideais, ou seja, aquelas que são exigidas para o trabalho e que, na visão do indivíduo, ele deveria possuir; e as competências reais, as quais referem-se às competências que o gestor considera que possui, isto é, que são reveladas por esse indivíduo. Essa diferença representa um norte para as ações de capacitação e, consequentemente, é considerada uma orientação para a melhoria da atuação gerencial (RODRIGUES \& VILLARDI, 2017).

Portanto, considerando-se os papéis gerenciais que o empreendedor deve desempenhar dentro da organização e as competências gerenciais necessárias para tal desempenho, contemplado no modelo de Quinn et al. (2003) utilizado na presente pesquisa, pretende-se responder a seguinte pergunta: como se configuram as competências gerenciais, ideais e reais, de empreendedores de startups de Belo Horizonte (MG), à luz de suas próprias percepções?

Este estudo teve como objetivo geral analisar como se configuram as competências gerenciais, ideais e reais, dos empreendedores de startups de Belo Horizonte (MG), segundo suas percepções. Em relação aos objetivos específicos, buscou-se verificar: (1) a lacuna existente entre o aspecto ideal e real; (2) quais as competências gerenciais a serem desenvolvidas pelos empreendedores, segundo suas próprias percepções; e (3) quais os pontos positivos e negativos do exercício gerencial em uma startup. 
Este artigo está estruturado em cinco partes, incluindo esta introdução, em que se apresentam o problema de pesquisa, o objetivo geral e os objetivos específicos. Na segunda seção, desenvolve-se o referencial teórico da pesquisa que aborda as startups, a função gerencial, as competências gerenciais e o modelo de Quinn et al. (2003). Na terceira seção, por sua vez, descreve-se a metodologia utilizada no presente estudo. Na quarta seção, apresentam-se os resultados; por fim, na quinta seção, formulam-se as considerações finais, limitações da pesquisa e recomendações para futuros trabalhos nesta temática.

\section{REFERENCIAL TEÓRICO}

\section{As Startups}

Nas últimas décadas, a sociedade tem presenciado significativas transformações econômicas, sociais, políticas e tecnológicas, com reflexo direto sobre as organizações, submetendo-as a buscarem novas estratégias para se adequarem às mudanças e para se manterem competitivas (SOARES \& MELO, 2009).

Nesse contexto, a inovação se tornou foco de diversas empresas por ser considerada elemento de destaque no desenvolvimento dos negócios e no sucesso empresarial (SCHUMPETER, 1988). Originaramse, assim, as chamadas "startups", empresas que têm conquistado cada vez mais espaço e participação no mercado (LOPES et al. 2017).

Segundo Brigidi (2009) e Hunt (2013), as startups são consideradas essenciais no âmbito econômico e representam uma fonte considerável de geração de emprego e de muitas inovações. Definem-se startups como empresas consideradas jovens, que se caracterizam como extremamente inovadoras em qualquer área ou ramo de atividade, que atuam em um ambiente de extrema incerteza e que buscam desenvolver um modelo de negócio escalável e repetível (ABSTARTUPS, 2018). Corroborando essa visão, Ries (2012, p. 26) apresenta que: "uma startup é uma instituição humana projetada para criar novos produtos e serviços sob condições de extrema incerteza".

Alberone, Carvalho e Kicorve (2012) diferenciam o estágio inicial das startups e das empresas tradicionais ao enfatizarem que as empresas tradicionais constroem um plano de negócio detalhado, procuram ver a sua viabilidade para, posteriormente, colocá-lo em ação. Por outro lado, as startups verificam, na tentativa e erro, se o empreendimento possui mercado e consumidores, compreendendo a campo se atendem às novas demandas ou não.

As startups também são consideradas empreendimentos que buscam riqueza, visão de curto prazo e rápido crescimento. Ressalta-se que o governo tem estimulado a abertura destas empresas, uma vez que proporcionam um bem-estar social, novos empregos e inovação para o país (DORNELAS, 2008). Hermanson (2011) aponta que a startup não precisa, necessariamente, ser uma empresa de tecnologia, mas esse empreendimento cresce mais na área de tecnologia devido aos baixos custos para criar uma empresa de software quando comparado a uma indústria.

Para Brigidi (2009), as startups estão em um contexto vantajoso para a sua abertura, visto que existem políticas de fomento à inovação, ao incentivo tecnológico e ao empreendedorismo, havendo, assim, novas oportunidades para começar negócios inovadores, principalmente com foco na alta tecnologia. 
Em outra perspectiva, Nagamatsu, Barbosa e Rebecchi (2013) afirmam que ainda existem diversos desafios no ambiente de negócios para as startups. Para os autores, os custos trabalhistas elevados, a alta carga tributária e a alta taxa de mortalidade dessas empresas nos seus primeiros anos representam obstáculos para a criação de novas startups. Ademais, por estarem inseridas em um mercado incerto e, consequentemente, não apresentarem qualquer tipo de garantia aos seus investidores, as startups, muitas vezes, possuem dificuldades de acesso a financiamentos (NAGAMATSU, BARBOSA \& REBECCHI, 2013).

Arruda et al. (2014, p. 6) apontam que "por estarem inseridos em um contexto tão novo e por possuírem características tão peculiares, poucos podem usufruir do conhecimento até então produzido sobre o empreendedorismo tradicional". Dessa forma, os autores reforçam que a aceitação do seu produto ou serviço pelo mercado e a capacidade de adaptação dos empreendedores às mudanças de cenário refletem na sobrevivência dessas organizações.

Além disso, segundo Figueira et al. (2017), o ambiente de incerteza e as particularidades das startups impactam, diretamente, seu gerenciamento. Estes autores abordam que, normalmente, a área de atuação dessas empresas se associa à formação ou ao interesse profissional dos seus empreendedores que, frequentemente, possuem apenas o conhecimento técnico sobre o empreendimento e pouca experiência ou competências de gestão.

Ainda assim, os empreendedores se deparam com diversos desafios gerenciais, principalmente voltados ao processo de recursos humanos e ao gerenciamento financeiro e estratégicos de sua empresa (FIGUEIRA et al., 2017). Complementarmente, Rocha (2008) afirma que as chances de crescimento dessas organizações estão relacionadas à motivação e capacidade de gerenciar o empreendimento. Dessa maneira, tendo em vista que os empreendedores, muitas vezes, assumem funções e cargos gerenciais em suas startups, destacam-se algumas teorias que caracterizam a função gerencial e as suas peculiaridades.

\section{Função Gerencial}

Diversas pesquisas tratam a função gerencial devido à diversidade de posicionamentos diante de seus obstáculos, características e habilidades do exercício da gerência, trabalho considerado repleto de contradições, ambiguidades e dilemas (ESTHER \& MELO, 2008). Levando em conta a sua complexidade, vários modelos sobre essa temática foram publicados nos últimos anos, encontrando-se em contínua discussão até os dias atuais (QUINN et al., 2003).

Observa-se que os estudos que tratam sobre a gerência apresentam dificuldades em retratar os limites, as atribuições, as prioridades e as expectativas das atividades gerenciais (MARRA \& MELO, 2005). Motta (1991) e Mintzberg (1986) contribuem para a temática ao abordar a função gerencial como algo peculiar e diferente das outras profissões, sendo de difícil definição, uma vez que "já se aceita tratar a função gerencial como extremamente ambígua e repleta de dualidades, cujo exercício se faz de forma fragmentada e intermitente" (MOTTA, 1991, p. 20).

Hill (1993), em seu estudo, ressalta o caráter multifacetado da gerência, apresentando as diversas habilidades e os esforços psicológicos necessários para o alcance dos objetivos organizacionais. A autora também expõe como os gerentes sentem-se sobrecarregados e entendem a ambiguidade e os conflitos como 
inerentes ao papel gerencial. A função gerencial é tida também como complexa e constituída de tensões, impondo aos gerentes a uma rotina com pressão, agitação e fragmentação (HILL,1993).

Enfatiza-se, segundo Motta (1991), a necessidade de o gerente possuir capacidade de decisão, de negociação, de enfrentamento de riscos e de liderança para atender as exigências do ambiente organizacional. No contexto específico das startups, estes enfrentam desafios ligados ao ambiente instável e à falta de preparo dos empreendedores para a gerência. Com isso, competências podem incorporar vantagem na sua atuação dentro dessas empresas, representando um diferencial no que tange à competitividade e ao sucesso organizacional (LOPES et al., 2017).

Assim, destaca-se que estes sujeitos deverão mobilizar competências diferenciadas e interdependentes em seu papel, dentre elas as competências gerenciais que irão permitir o alcance de resultados voltados para a estratégia institucional.

\section{Competências Gerenciais e o Modelo de Quinn et al. (2003)}

As competências gerenciais estão vinculadas aos gestores e, por conseguinte, refletem no seu desempenho durante o trabalho e no cumprimento dos seus papéis organizacionais. Elas devem estar alinhadas à estratégia organizacional e seus objetivos, com a finalidade de proporcionar melhorias nos seus resultados (PICCHIAI, 2003).

Segundo Ruas (2005, p. 48), as competências gerenciais representam um conjunto de capacidades articuladas e desenvolvidas pelo gestor em uma situação específica, que possibilita o alcance de resultados voltados para o cumprimento dos objetivos organizacionais. Para o autor, competência gerencial vincula-se à "capacidade de mobilizar, integrar e colocar em ação conhecimentos, habilidades e formas de atuar, a fim de atingir/superar desempenhos configurados na missão da empresa e da área" (RUAS, 2005, p. 96).

Paiva e Couto (2008), por sua vez, afirmam que o gerente é um ator estratégico no alcance das metas empresariais, visto que é o responsável pelos processos de modernização e reestruturação a serem realizados na organização, e, com isso, devem aprender a tentar, errar, criar e inovar dentro da empresa.

No caso dos gestores das startups, as competências em questão abrangem particularidades, visto que os papéis a desempenhar por estes sujeitos são específicos. Nesse sentido, o estudo de Quinn et al. (2003) se destaca por associar e aproximar os construtos papel e competência gerencial. Entende-se competência gerencial como a capacidade de impulsionar a equipe ao conhecimento, viabilizar metas, solucionar problemas, trazendo aprendizado, excelência, autogestão e resultado (QUINN et al., 2003).

Para os autores, tornou-se um desafio atingir a eficácia organizacional no atual ambiente dinâmico em que se encontram as organizações. Em seu estudo, Quinn et al. (2003) expõem que não existe apenas um modelo único que oriente os gerentes para a estratégia organizacional e, por isso, abordam quatro modelos de gestão em uma matriz mais vasta, subdividida em: nível de institucionalização de processos (flexibilidade ou controle) e foco (interno ou externo).

Assim, apresentam-se os quatro modelos de gestão diferentes entre si que dão base para as ações modernas gerenciais: (1) o modelo de relações humanas, que foca na abertura, participação, moral e compromisso; (2) o modelo de sistemas abertos, que se destina à adaptação, ao crescimento, à aquisição de recursos e à inovação; (3) o modelo de metas racionais, que se relaciona à direção, à produtividade, à 
realização e à clareza de objetivos; e, por fim, (4) o modelo de processos internos, que prioriza o controle, o gerenciamento de informações, a documentação e a estabilidade (QUINN et al., 2003).

Para Quinn et al. (2003), os quatro modelos apresentados são considerados subdomínios interligados que fazem parte de um construto maior: a eficácia organizacional. Com isso, de maneira isolada, os modelos não conseguem alcançar a eficácia organizacional, sendo necessário vê-los como parte de um arcabouço maior, relacionado ao "quadro de valores competitivos", representada na Figura 1.

Figura 1 - As competências e papéis dos líderes no quadro de valores competitivos

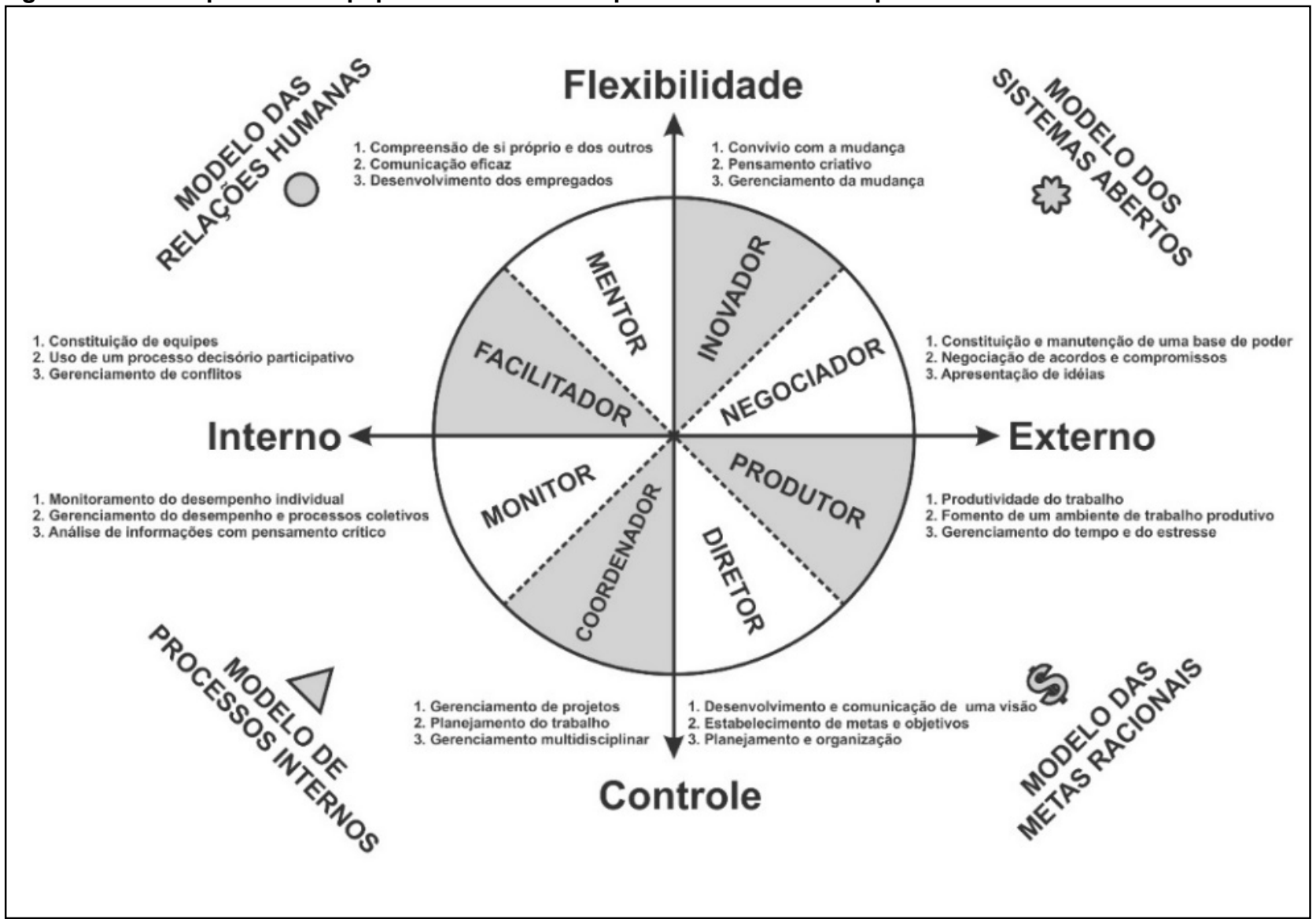

Fonte: Quinn et al. (2003, p. 14)

Destaca-se que algumas estratégias são eficazes em um contexto e, por outro lado, não são em outras. Portanto, para os autores, o ideal seria o desempenho efetivo em todos os quatro modelos, simultaneamente. Dessa forma, aqueles que exercem a função gerencial devem desempenhar seus papéis com competências, demonstrando resultados reconhecidos por ele mesmo e por seus atores, o que acreditam ser um perfil eficaz.

Nota-se que os oito papéis estão representados acima no quadro de valores, compreendendo as três competências intrínsecas a cada papel. Essas competências são tidas como essenciais para o desenvolvimento dos oito papéis, complementam aquelas com as quais fazem fronteira e, concomitantemente, contrastam-se com aquelas com as quais se opõe.

Ressalta-se que os gerentes que apresentam uma maior complexidade de comportamento e demonstram desempenhar papéis apontados como contraditórios, constantemente, são considerados melhores líderes (QUINN et al. 2003). 
Destarte, é necessário desenvolver-se e aprimorar-se a fim de desempenhar papéis que não se parecem com o estilo natural do indivíduo, visando, consequentemente, tornar-se um melhor gerente. Para Quinn et al. (2003), é preciso ter capacidade de equilibrar os distintos papéis de maneira adequada, focando no aprendizado e na constante transição desafiadora da gestão.

\section{METODOLOGIA DE PESQUISA}

O estudo se caracteriza como teórico-empírico, de campo, descritivo e de natureza qualitativa (VERGARA, 2009; LAKATOS \& MARCONI, 2003; GIL, 1996). A pesquisa de campo associa-se à investigação do fenômeno pesquisado dentro do seu ambiente, podendo ser realizada por meio de questionários, observação participante ou testes (VERGARA, 2009).

A pesquisa descritiva, por sua vez, baseia-se em explorar melhor a comunidade, seus comportamentos e suas características, gerando informações mais detalhadas durante a pesquisa (TRIVIÑOS, 1987). A abordagem qualitativa foi escolhida devido à necessidade de aprofundamento do tema do estudo em questão, visto que se buscou responder a questões particulares, específicas de um determinado contexto (MINAYO, 2004).

No que tange aos sujeitos da pesquisa, foram selecionados 7 empreendedores que atuavam em cargos gerenciais, de uma amostra de 7 startups localizadas em Belo Horizonte (MG), cujos autores possuíam acesso. A amostra foi não probabilística, e os sujeitos que participaram do estudo foram escolhidos a partir do critério de acessibilidade e intencionalidade, conforme propõe Vergara (2009).

No tocante à coleta de dados, foram utilizados dois questionários: o primeiro relacionado à identificação do perfil da startup e o segundo com questões referente aos dados sociodemográficos e funcionais do empreendedor-gestor. Também foi realizada uma entrevista semiestruturada abordando as competências gerenciais (ideais e reais), à luz do modelo conceitual de Quinn et al. (2003), que possibilitou a compreensão do objetivo geral do presente estudo. Foram feitas 11 perguntas abertas durante a entrevista, gravadas de maneira a acelerar o processo de coleta e garantir a fidedignidade das informações fornecidas. A fala dos respondentes foi codificada (E1, E2, E3...) com o propósito de preservar a identidade dos sujeitos participantes.

O tratamento de dados foi feito por meio da técnica de análise de conteúdo, que conforme Bardin (2008, p. 37): "consiste em apurar questões de conteúdo muito aproximativas, subjetivas, para pôr em evidência com objetividade a natureza e as forças relativas aos estímulos a que o sujeito é submetido". O procedimento da análise de conteúdo foi realizado conforme os moldes de Melo et al. (2007), sendo operacionalizado em três etapas, na qual a primeira refere-se à preparação dos dados, a segunda associase à tabulação quantitativa e a terceira relaciona-se à análise ou categorização temática.

Ao final, utilizou-se, também, estatística descritiva para evidenciar as características da amostra pesquisada. 


\section{ANÁLISE E RESULTADOS}

Para compreender o perfil das startups, foram selecionados 7 empreendedores em cargos gerenciais para responderem as questões referentes à descrição do negócio, ao tempo da empresa, à quantidade de empregados e a quantidade de gestores na organização. O Quadro 1 apresenta a síntese das informações.

Quadro 1: Perfil das startups

\begin{tabular}{|c|c|c|c|c|c|}
\hline Entrevistado & $\begin{array}{c}\text { Descrição do negócio da } \\
\text { startup }\end{array}$ & $\begin{array}{l}\text { Tempo } \\
\text { da } \\
\text { empresa }\end{array}$ & $\begin{array}{c}\text { Quantidade } \\
\text { de } \\
\text { empreendedores }\end{array}$ & $\begin{array}{l}\text { Quantidade } \\
\text { de gestores }\end{array}$ & $\begin{array}{c}\text { Quantidade de } \\
\text { empregados }\end{array}$ \\
\hline E1 & $\begin{array}{l}\text { Aplicativo para celular que } \\
\text { vende microfranquias de } \\
\text { agências de intercâmbio. }\end{array}$ & $\begin{array}{l}2 \text { anos e } \\
8 \text { meses }\end{array}$ & r & 1 & 2 \\
\hline E2 & $\begin{array}{l}\text { Plataforma online de } \\
\text { venda pré-paga de } \\
\text { combustíveis }\end{array}$ & 9 meses & 2 & 2 & 1 \\
\hline E3 & $\begin{array}{c}\text { Software as a service } \\
\text { (SaaS) de geração de } \\
\text { leads qualificados com } \\
\text { experiência de compras } \\
\text { bonificadas }\end{array}$ & 1 ano & 2 & 4 & 4 \\
\hline E4 & $\begin{array}{l}\text { Plataforma digital que } \\
\text { oferece vídeos de } \\
\text { exercício físico, } \\
\text { nutricionista e } \\
\text { monitoramento corporal } \\
\text { online. }\end{array}$ & $\begin{array}{c}1 \text { ano e } 4 \\
\text { meses }\end{array}$ & 3 & 4 & 1 \\
\hline E5 & $\begin{array}{c}\text { Desenvolvimento de } \\
\text { Software web e mobile sob } \\
\text { demanda personalizada }\end{array}$ & 1 ano & 2 & 2 & 4 \\
\hline E6 & $\begin{array}{l}\text { Marketplace que fornece o } \\
\text { gerenciamento da locação } \\
\text { de veículos particulares } \\
\text { para motoristas de } \\
\text { plataformas de transporte. }\end{array}$ & 2 anos & 2 & 5 & 3 \\
\hline E7 & $\begin{array}{l}\text { Plataforma digital que } \\
\text { oferece curso de inglês } \\
\text { online. }\end{array}$ & 8 meses & 1 & 1 & 1 \\
\hline
\end{tabular}

Fonte: Elaborado pelos autores

Em relação ao questionário sociodemográfico e funcional, questionou-se qual cargo ou função gerencial o empreendedor exercia, qual o regime de trabalho, as horas de trabalho semanais em média e se tiveram experiência de gestão anterior à criação da empresa. Apresentam-se, no Quadro 2, as principais informações referentes ao perfil dos entrevistados. 
Quadro 2: Perfil dos entrevistados

\begin{tabular}{|c|c|c|c|c|c|}
\hline Entrevistado & Idade & Cargo atual & $\begin{array}{c}\text { Regime de } \\
\text { Trabalho }\end{array}$ & $\begin{array}{c}\text { Horas de trabalho } \\
\text { por semana em } \\
\text { média }\end{array}$ & $\begin{array}{c}\text { Experiência de } \\
\text { gestão anterior }\end{array}$ \\
\hline E1 & 23 anos & Diretor(a) executivo(a) & Integral & $40 \mathrm{~h}$ & Não \\
\hline E2 & 23 anos & Diretor(a) de operações & Integral & $40 \mathrm{~h}$ & Não \\
\hline E3 & 45 anos & Diretor(a) executivo(a) & Integral & $60 \mathrm{~h}$ & Sim \\
\hline E4 & 40 anos & Diretor(a) comercial & Parcial & $14 \mathrm{~h}$ & Sim \\
\hline E5 & 23 anos & $\begin{array}{c}\text { Diretor(a) financeiro(a) } \text { c } \\
\text { comercial }\end{array}$ & Integral & $40 \mathrm{~h}$ & Sim \\
\hline E6 & 25 anos & Diretor(a) financeira & Integral & $60 \mathrm{~h}$ & Não \\
\hline
\end{tabular}

Fonte: Elaborado pelos autores

Dos 7 entrevistados, 2 são do sexo feminino e 5 do sexo masculino. Em relação à faixa etária, observa-se que a maioria possui idade igual ou inferior a 25 anos. No que tange ao estado civil, 5 entrevistados são solteiros, 1 é casado e 1 é divorciado/separado. Quanto à escolaridade, 2 possuem ensino superior incompleto, 3 possuem ensino superior completo e 2 possuem especialização. Enfatiza-se que todos os empreendedores assumiram o cargo gerencial atual desde a criação da empresa. Destes, 3 não possuíam experiência gerencial anterior em outra empresa. No tocante ao regime de trabalho, apenas 2 gestores atuam em regime parcial, conciliando suas atividades na startup com outros empreendimentos. E, por fim, 2 empreendedores-gestores trabalham, em média, menos de 25 horas por semana, 3 trabalham 40 horas semanais e 2 alegaram trabalhar aproximadamente 60 horas por semana.

Por meio das entrevistas semiestruturadas, percebeu-se que, em relação à trajetória profissional, todos os entrevistados passaram por experiências profissionais em outras empresas que contribuíram para a decisão de montar e gerir uma startup. Quando questionados sobre quais as competências que um gestor de startup deveria possuir, os relatos mais encontrados relacionaram-se a: "ser organizado(a)" (E1, E2, E3, E4, E5, E6, E7); "saber gerir metas" (E2, E3, E5, E6, E7); "ser estudioso(a)" (E1, E4, E5, E6, E7); "trabalhar em equipe" (E1, E2, E3, E7); "saber gerir pessoas" (E1, E2, E5, E7). Na Tabela 1, essas e outras respostas foram sintetizadas e apresentadas de acordo com papel gerencial correspondente, segundo o modelo de Quinn et al. (2003).

Tabela 1: Competências ideias do gestor de startup na opinião dos entrevistados

\begin{tabular}{cccc}
\hline Respostas & Papel & Entrevistados & Total \\
\hline Ser organizado(a) & Diretor & E1, E2, E3, E4, E5, E6, E7 & 7 \\
Saber gerir metas & Diretor & E2, E3, E5, E6, E7 & 5 \\
Ser estudioso(a) & Monitor & E1, E4, E5, E6, E7 & 5 \\
Trabalhar em equipe & Facilitador & E1, E2, E3, E7 & 4 \\
Saber gerir pessoas & Facilitador & E1, E2, E5, E7 & 4 \\
Saber planejar & Diretor & E1, E4, E5 & 3 \\
Ter controle/ser crítico & Monitor & E4, E5, E6 & 3 \\
Ser inovador(a) e criativo(a) & Inovador & E1, E3, E7 & 3 \\
Saber gerir mudanças & Inovador & E2, E3, E4 & 3 \\
Ser líder & Coordenador & E3, E4 & 2 \\
Saber se comunicar & Mentor & E3, E5 & 2 \\
\hline
\end{tabular}

Fonte: Elaborada pelos autores 
Verifica-se a preponderância dos papéis de diretor, facilitador, monitor e inovador, a incidência dos papéis de coordenador e mentor, bem como a ausência de menções aos papéis de negociador e de produtor.

O papel de diretor, por sua vez, faz referência às competências de desenvolvimento e comunicação de uma visão, estabelecimento de metas e objetivos e planejamento e organização (QUINN et al., 2003), que são relatadas a seguir.

Eu acho que um gestor deve ter os seus objetivos e a visão de caminho de futuro bem alinhados, porque assim todos vão trabalhar de forma mais sincronizada. (E2)

Eu acho que um gestor de startup precisa de ter um equilibrio grande entre a habilidade de organizar uma empresa e manter as suas metas, já que a empresa não tem histórico nem dados para embasar o seu trabalho. Mesmo assim, ela precisa disso neste primeiro momento para garantir sua sobrevivência. (E5)

Um gestor tem que ser uma pessoa organizada, que saiba perceber qual é o objetivo da empresa em si, aonde ela quer chegar e segmentar isso com metas e objetivos. (E6)

Segundo Quinn et al. (2003), o papel de facilitador diz respeito à constituição de equipes, ao uso de um processo decisório participativo e ao gerenciamento de conflitos, sendo identificados como necessários ao gestor pelos entrevistados.

O empreendedor-gestor deve ser uma pessoa que consegue unir as qualidades das pessoas da sua equipe com as necessidades que a empresa possui. (E1)

É muito importante gerir pessoas porque na verdade todo o seu planejamento e gestão dependem das pessoas, se elas não se comprometerem, nada vai para frente. (E5)

A pessoa tem que ter um nível de controle, de saber liderar, porque você não consegue chegar lá sozinho. (E6)

O gestor deve colocar coisas em práticas, motivar a equipe em sempre fazer mais e melhor. A equipe olha muito o que os empreendedores gestores estão fazendo, como se portam e gerenciam. O time se inspira em nós. (E7) 
O papel de monitor reflete as competências de monitoramento do desempenho individual, de gerenciamento do desempenho e processos coletivos e de análise de informações com pensamentos críticos. Essas competências são encontradas nos trechos reproduzidos a seguir.

É muito importante que o gestor-empreendedor pesquise e estude, que ele tenha conhecimento para entender qual ferramenta vai te ajudar. (E3)

Em termos de característica, um gestor precisa ser destemido e estudioso, porque é um tiro no escuro. Quando é o próprio empreendedor, mesmo sendo o dono do negócio, ele tem que ser humilde o suficiente para entender que não sabe nada, porque tudo na startup é novo. (E4)

O papel inovador é caracterizado pelo convívio com a mudança, pelo pensamento criativo e pelo gerenciamento da mudança (QUINN et al., 2003), que são mencionados pelos entrevistados.

Um gestor de startup deve ser bastante cabeça aberta, uma pessoa que sempre deve estar com a cabeça voltada para a inovação, já que a ideia da startup é sempre sair daquilo que é mainstream, daquilo que é comum no mercado, e trazer inovação, coisas novas para o mercado. (E1)

A startup é um modelo disruptivo, então é difícil ter uma receita de bolo, cada startup aprende um jeito diferente, por isso é preciso ser inovador, pensar fora da caixa. (E3)

Um gestor de startup ou um empreendedor tem que ser bastante inovador, ter ideias inovadoras e disruptivas. Deve querer fazer a diferença. Normalmente uma startup é criada para conseguir ajudar um certo tipo de pessoa, com algum certo tipo de necessidade que hoje as empresas tradicionais não conseguem suprir. (E7)

Observa-se que o modelo de gestão considerado ideal pelos respondentes está direcionado tanto para o controle, com ênfase para os papéis de monitor e diretor, quanto para a flexibilidade, com destaque para os papéis de facilitador e inovador. Além disso, direcionam-se também para o foco externo, com os papéis de inovador e diretor, e para o foco interno, com destaque para os papéis de facilitador e monitor, e com a incidência dos papéis de coordenador e mentor. 
Quando questionados sobre as competências que os gestores possuíam em suas próprias percepções, destacaram-se as respostas apresentadas na Tabela 2.

Tabela 2: Competências reais do gestor de startup na opinião dos entrevistados

\begin{tabular}{|c|c|c|c|}
\hline Respostas & Papel & Entrevistados & Total \\
\hline Saber se comunicar & Mentor & $\mathrm{E} 1, \mathrm{E} 3, \mathrm{E} 4, \mathrm{E} 5$ & 4 \\
\hline Ser estudioso(a) & Monitor & $\mathrm{E} 1, \mathrm{E} 4, \mathrm{E} 7$ & 3 \\
\hline Ser inovador(a) e criativo(a) & Inovador & E1, E3, E7 & 3 \\
\hline Ser organizado(a) & Diretor & E4, E6 & 2 \\
\hline Saber planejar & Diretor & E5 & 1 \\
\hline Saber gerir metas & Diretor & E2 & 1 \\
\hline Ter controle/ser crítico & Monitor & E5 & 1 \\
\hline Saber gerir pessoas & Facilitador & E4 & 1 \\
\hline
\end{tabular}

Fonte: Elaborada pelos autores

Verifica-se, no aspecto real, a preponderância dos papéis de mentor, monitor, inovador, diretor e a incidência do papel de facilitador, bem como a ausência dos papéis de negociador, produtor e coordenador. Os trechos a seguir ilustram o papel de mentor, cujas competências se relacionam com a comunicação eficaz, com compreensão de si próprio e dos outros e com desenvolvimento dos empregados.

Eu sempre converso muito com as pessoas que trabalham comigo, e todas as ideias serem construídas com mais de 1 mão é uma coisa que contribui bastante. E esse dia a dia com as pessoas dentro da startup é uma coisa que ajuda, porque a gente sai um pouco do nosso mundinho, das nossas ideias que temos na nossa cabeça, que às vezes pode parecer genial, mas quando a gente conversa com os outros e ajusta, a gente sempre consegue chegar no melhor caminho. (E1)

Gosto muito de lidar com pessoas, então eu tenho uma facilidade muito grande com meu grupo e com as pessoas que eu trabalho. Eu acho que acima de tecnologia, acima de tudo, pessoas são o principal recurso da minha empresa. [...] Gestão de pessoas, entender e saber conversar com as pessoas para que a mensagem seja entendida são meus pontos fortes. (E3)

Naturalmente eu sou bom com pessoas, sou bom em me comunicar e entender o outro. (E4)

Eu acho que sempre fez parte do meu perfil me comunicar muito bem. Tenho muita facilidade em transformar conceitos em ideias e passar elas para as pessoas, então tenho uma boa habilidade de transmitir credibilidade. Então na hora de uma reunião com o cliente ou em uma reunião com os acionistas, eu consigo transmitir meu ponto de uma maneira que entendem o que estou falando. (E5) 
Em relação ao papel de monitor, associado a análise, pensamento crítico e desempenho individual e coletivo, destacam-se as seguintes falas:

Eu estudo bastante. É a coisa que eu acho que, antes de colocar em prática, se a gente souber a teoria, isso facilita bastante, faz com que a gente bata menos cabeça na parede. (E1)

Para mim a melhor forma de trazer informação são três maneiras principais: leitura, estudo individual e mentorias. (E4)

E o que eu vim agregando para a área de gestão da startup foi a parte de controle mesmo, de ser crítico e cobrar. Temos alguns atritos às vezes, mas de modo geral o entendimento de todo mundo aqui é bom, é importante ter uma pessoa colocando um freio nas decisões. Me dou o trabalho de ser mais minucioso nas informações que eu busco para poder tomar alguma decisão. (E5)

Eu sempre estou estudando, até porque as startups estão em um ambiente em constante mudança, então é necessário se atualizar e adquirir o máximo de conhecimento possível. (E7)

Observa-se que os trechos a seguir fazem referência ao papel de inovador, vinculado à criatividade e à mudança:

A parte de ideação, de ideologia, de ter várias ideias bacanas, de querer mudar a sociedade em que a gente vive é uma coisa que eu tenho bastante em mim. (E1)

Eu sou muito criativo, muito inovador. (E3)

Eu possuo boas ideias inovadoras em relação à estratégia do negócio, ao caminho a ser corrido, de forma que os potenciais clientes vão se interessar mais. Acho que a vontade de inovar e querer impactar pessoas é uma coisa natural para mim. (E7) 
O papel de diretor, que abrange o desenvolvimento e a comunicação de uma visão e associa-se às metas, objetivos, organização e planejamento, apresenta-se nas seguintes falas dos entrevistados:

[...] essa visão de metas e evolução do sistema, das aplicações da venda comercial, a gente trabalha muito. Também temos bem alinhado o que pretendemos fazer para o futuro pelo menos nos próximos 9 a 12 meses. (E2)

Eu acho que tenho um bom senso de planejamento, inclusive foi o motivo pelo qual eu assumi também a gestão da empresa, porque a galera da área tecnológica tem isso muito forte de testar, de experimentar, de ver coisa nova. E o que eu vim agregando na gestão foi a parte de planejamento e controle mesmo. (E5)

Eu sou uma pessoa extremamente organizada [...] Organização é natural meu, segmentar o que precisamos fazer daqui para a frente e fazer o passo a passo é meu. (E6)

Nota-se que o modelo de gestão real-efetivo dos respondentes está direcionado para os dois níveis de institucionalização de processos. No que tange ao controle, encontram-se os papéis de monitor e diretor, também mencionados no aspecto ideal. Já na flexibilidade, percebeu-se um destaque para os papéis de mentor e inovador e a incidência do papel de facilitador, representando uma lacuna entre o ideal e o real, visto que o papel de facilitador obteve maior destaque e exigência na atuação ideal do que a encontrada no real. Além disso, direcionam-se também para os dois focos do modelo de Quinn et al. (2003). No foco externo, foram mencionados os papéis inovador e diretor, assemelhando-se ao ideal. No tocante ao foco interno, encontraram-se os papéis de mentor e monitor, com a incidência do papel de facilitador.

Quando perguntados sobre as competências que esses profissionais deveriam desenvolver, ou seja, da lacuna existente entre o ideal e o real, observou-se que esses profissionais acreditam que precisam desenvolver as seguintes competências gerenciais - Tabela 3.

Tabela 3: Competências a serem desenvolvidas pelos gestores de startup na opinião dos entrevistados

\begin{tabular}{|c|c|c|c|}
\hline Respostas & Papel & Entrevistados & Total \\
\hline Ser organizado(a) & Diretor & $\mathrm{E} 1, \mathrm{E} 2, \mathrm{E} 3, \mathrm{E} 7$ & 4 \\
\hline Trabalhar em equipe & Facilitador & E4, E5, E6 & 3 \\
\hline Saber se comunicar & Mentor & E2 & 1 \\
\hline Monitorar e ter análise crítica & Monitor & E5 & 1 \\
\hline Saber conviver com mudanças & Inovador & E6 & 1 \\
\hline Produtividade no trabalho & Produtor & E1 & 1 \\
\hline
\end{tabular}

Fonte: Elaborada pelos autores 
Os relatos mais recursivos foram referentes: à organização (E1, E2, E3, E7), vinculado ao papel de diretor, e a trabalhar com a equipe (E4, E5, E6), relacionado ao papel de facilitador. Os trechos a seguir referem-se ao papel de diretor:

A organização dessa parte teórica para ela virar prática foi a parte que eu mais tenho trabalhado para desenvolver. (E1)

Eu acho um desafio me organizar para definir o grau de importância de cada tarefa. Porque às vezes eu acabo fazendo uma tarefa que eu considero importante, mas que na visão geral não é importante e a gente acaba destoando e deixando coisas que não deveriam ser deixadas. (E2)

O senso de organização não é tão natural para mim. Eu acho que todo criativo tem esse problema de ter que pensar 10 coisas ao mesmo tempo, mas se organizar é uma coisa que não é natural em mim, eu tenho que trabalhar e desenvolver isso. (E3)

Uma característica muito importante que ainda tenho que desenvolver é a minha organização. (E7)

Têm-se a seguir os trechos que indicam a dificuldade de alguns entrevistados em lidar com a equipe, competência representada pelo papel de facilitador, também considerada como lacuna ao verificar as competências consideradas ideias e reais pelos respondentes:

Muitas coisas eu ainda não consigo alinhar devido à diferença de idade com minhas sócias, muitas vezes o meu senso de ordem é diferente do senso delas. Temos uma questão de respeito mútuo, mas muitas vezes não funciona como eu gostaria. (E4)

Uma coisa que eu tenho que desenvolver é que eu venho de uma formação tradicional, então tem momentos que eu me sinto desconfortável com deixar as coisas correrem soltas, isso gera conflitos com meus colegas, mas entendo que tem momentos que é exatamente isso que precisa ser feito. (E5)

Sou considerada chata e metódica aqui dentro, às vezes até demais. Mas tento aprender com meus sócios a ser menos, porque startup, a gente tem que ter uma certa mobilidade, não dá pra ser tão rígido. (E6) 
Em seguida, o estudo também buscou compreender os aspectos positivos e negativos do trabalho na gerência em uma startup. Com isso, como aspecto positivo, as respostas mais recorrentes foram: "aprender constantemente" (E1, E3, E4, E5) e "gostar do trabalho" (E2, E3, E6). Esses dados estão representados na Tabela 4, em conjunto com outras respostas:

Tabela 4: Pontos positivos do exercício gerencial nas startups

\begin{tabular}{ccc}
\hline Respostas & Entrevistados & Total \\
\hline Aprender constantemente & E1, E3, E4, E5 & 4 \\
Gostar do trabalho & E2, E3, E6 & 3 \\
Poder agregar para a sociedade & E2, E7 & 2 \\
Adquirir experiência e novas responsabilidades & E1 & 1
\end{tabular}

Fonte: Elaborada pelos autores.

Os trechos a seguir expõem as respostas que ilustram os dados apresentados na Tabela 4:

Primeiramente é positivo adquirir experiência, tanto de assumir responsabilidades que antes a gente não estava acostumado e aprender constantemente. (E1)

Positivo porque é bem gratificante que um negócio que a gente montou do zero está caminhando e dando certo. (E2)

O lado positivo é aprender sempre. Como é seu, e como é uma coisa que você acredita, você acaba extrapolando a carga horária, isso é gostoso porque você não vê o tempo passar. (E3)

Positivo é o aprendizado. (E4)

O ponto positivo é o constante aprendizado. Como não temos tanto braço, todo mundo faz um pouco de tudo, aí você acaba aprendendo um pouco de todas as áreas na empresa, isso agrega muito. (E5)

O ponto positivo é que adoro meu negócio, combina muito comigo. (E6)

Pontos positivos é poder fazer parte de uma equipe de mudança, de poder agregar para a sociedade. Poder colocar as ideias que a gente tem na prática, ter a oportunidade de realmente conseguir aplicar algumas coisas que, se a gente não tivesse nesse meio, ficaríamos apenas no mundo das ideias. (E7) 
Quando questionados sobre quais eram os pontos negativos do exercício gerencial nas empresas startups, a maioria dos entrevistados se referiu à "incerteza" (E3, E6, E7) e ao "risco" (E2, E6, E7), seguida da "insegurança" (E1, E3) e das "frustrações diárias" (E4, E5) que acontecem neste ambiente. A Tabela 5 apresenta as respostas encontradas no estudo:

Tabela 5: Pontos negativos do exercício gerencial nas startups

\begin{tabular}{ccc}
\hline Respostas & Entrevistados & Total \\
\hline Incerteza & E3, E6, E7 & 3 \\
Risco & E2, E6, E7 & 3 \\
Insegurança & E1, E3 & 2 \\
Frustrações diárias & E4, E5 & 2 \\
Pressão & E2 & 1 \\
\hline
\end{tabular}

Fonte: Elaborado pelos autores.

Os relatos a seguir ilustram os posicionamentos dos entrevistados:

É justamente ter responsabilidades novas é uma coisa positiva porque a gente aprende, mas também é negativo porque, por falta de experiência, a gente costuma tomar algumas decisões erradas, várias responsabilidades que a gente não estava acostumado caem sobre a gente e fica uma certa insegurança para saber se estamos indo para o caminho certo ou não. Além disso, ter todo o risco envolvido do negócio é uma coisa que não sabemos se vai ter tração no mercado, se o mercado vai absorver a ideia. (E1)

Às vezes o que acho negativo é que é uma pressão muito grande, porque, se você errar, você não tem mais o seu trabalho, se você errar, a sua startup que não vai dar certo. (E2)

Como negativo, é a incerteza. Toda startup, até validar o seu modelo de negócio, você não sabe se é um negócio mesmo. Então você sempre tem um pontinho de insegurança e de incerteza. (E3)

Negativo são frustrações que temos todo dia, por sermos novos no mercado, não ter adesão suficiente, as pessoas às vezes não dão feedback. Então o negativo são as frustrações diárias do processo. (E4)

Como ponto negativo me deixa um pouco frustrado lidar com a bagunça dos controles que fazem parte do dia a dia de startup, porque eu sou um pouco controlador. Então é uma frustração constante ter que ser a pessoa que discorda de todo mundo e que é o chato. (E5) 
Como você é gestor e sócio, você está correndo o risco ali junto. (E6)

Pontos negativos é o medo de não dar certo, medo das pessoas não gostarem, de achar que está indo no caminho certo e, na verdade, não ser esse o caminho correto e quebrar a cara mais pra frente. (E7)

Nota-se que, por ser considerada uma empresa inovadora e por estar inserida em um ambiente de incerteza (ABSTARTUPS, 2018; RIES, 2012), são mencionados aspectos positivos e negativos do cargo gerencial nestas organizações, o que representa uma certa ambiguidade no exercício do papel gerencial nas startups, conforme já apresentado por Mintzberg (1986), Motta (1991) e Hill (1993) em seus trabalhos sobre gerência.

Conclui-se que, como aspectos positivos, o prazer no trabalho, o aprendizado constante, as experiências profissionais e a possibilidade de agregar para a sociedade são tidos como benefícios do empreendimento e da gerência nas startups. Por outro lado, as condições que vivenciam estas empresas e seus atores implicam alguns aspectos negativos, tais como: o sentimento de incerteza e insegurança, os riscos inerentes ao cargo neste tipo de organização, as frustrações diárias e a constante pressão que vivenciam no empreendimento e na gerência.

\section{CONSIDERAÇÕES FINAIS}

Esta pesquisa teve como objetivo geral analisar como se configuram as competências gerenciais, ideais e reais, dos empreendedores de startups de Belo Horizonte (MG), segundo suas percepções, baseando-se no modelo de Quinn et al. (2003). Para isso, foi desenvolvido um estudo teórico-empírico, de campo, de abordagem qualitativa e descritiva, em que foram realizadas 7 entrevistas com empreendedores de startups que atuam em cargos gerenciais.

Diante do exposto, ressalta-se a importância da busca por minimizar a lacuna existente entre os papéis que vêm sendo idealizados e efetivamente realizados pelos gestores de startups, visando alcançar o equilíbrio entre o ideal e o real. Observa-se, no presente estudo, que os papéis que ganharam destaque no aspecto ideal foram os de diretor, facilitador, monitor, inovador, com a incidência dos papéis de mentor e de coordenador. Já no que tange ao real, os sujeitos mencionaram possuir os papéis de diretor, inovador, mentor e monitor, com a incidência do papel de facilitador.

Portanto, a fim de responder ao primeiro objetivo específico, a saber, a lacuna existente entre o ideal e o real, enfatiza-se no presente trabalho os papéis de coordenador e facilitador. Nota-se que o papel de facilitador obteve maior destaque e exigência na atuação ideal do que a encontrada no real, e, paralelamente, o papel de coordenador também foi mencionado nas competências ideais, mas não foi apresentado como competências reais exercidas pelos empreendedores na atividade gerencial. Além disso, para se responder ao segundo objetivo específico, durante as entrevistas, ao serem questionados sobre as competências a serem desenvolvidas, muitos alegaram desejar melhorar a sua relação com a equipe, competência associada ao papel de facilitador. Ainda, devido a sua importância, o papel de diretor também se encontra como enfoque para o desenvolvimento, segundo os entrevistados. 
Vale destacar que, para ser um melhor gerente, é necessário apresentar uma maior complexidade de comportamento e demonstrar desempenhar papéis apontados como contraditórios, sendo essencial o desenvolvimento dos oito papéis do quadro de valores competitivos, exposto na Figura 1 deste trabalho. Portanto, os gestores das startups devem ainda apresentar os papéis de negociador e produtor, não mencionados com frequência pelos sujeitos da pesquisa, a fim de ter uma maior capacidade de equilibrar os distintos papéis de maneira adequada, demonstrando possuir o que Quinn et al. (2003) acreditam ser um perfil eficaz.

No que tange ao terceiro objetivo específico, os pontos positivos do cargo gerencial nas startups que tiveram destaques referem-se ao aprendizado constante, ao gosto pelo trabalho, à possibilidade de agregar para a sociedade e às experiências e às novas responsabilidades características da função nessas organizações inovadoras. Já em relação aos pontos negativos, a incerteza, o risco e a insegurança foram os relatos mais frequentes.

Destacam-se as limitações do presente estudo e algumas recomendações para trabalhos futuros. No tocante à generalização dos achados da pesquisa, os resultados obtidos não poderão ser projetados e nem generalizados, uma vez que a quantidade de participantes deste estudo possui essa limitação (YIN, 2010). Por esse motivo, são relevantes novas pesquisas sobre o tema que possibilitem a sua generalização.

Outra possível limitação refere-se à restrição dos sujeitos de pesquisa, visto que, segundo Fleury e Fleury (2001), o conceito de competência também engloba o reconhecimento por terceiros. Portanto, recomenda-se abordar outros atores envolvidos na gestão das startups, podendo trazer uma compreensão mais aprofundada desta temática.

\section{REFERÊNCIAS}

ABSTARTUPS. Associação Brasileira de Startups. Disponível em: http://www.abstartups.com.br> Acesso em: abril de 2018.

ALBERONE, M.; CARVALHO, R.; KIRCOVE, B. Sua ideia ainda não vale nada: o guia prático para começar a validar seu negócio. Rio de Janeiro: 2012.

ARRUDA, C. et al. As causas da mortalidade de startups brasileiras. Núcleo de Inovação e Empreendedorismo, Fundação Dom Cabral, 2014.2 Disponível em <https://www.fdc.org.br/blogespacodialogo/Documents/2014/causas_mortalidade_startups_brasileiras.pdf>. Acesso em 05 de abril de 2018.

AZIZ, S.; MULLINS, M. E.; BALZER, W. K.; GRAUER, E.; BURNFIELD, J. L.; LODATO, M. A.; COHEN-POWLESS, M. A. C. Understanding the training needs of department chairs. In. Studies in Higher Education, v. 30, n. 5, p. 571-593, 2005.

BARDIN, L. Análise de conteúdo. Lisboa: Edições 70, 2008.

BRIGIDI, G. M. Criação de conhecimento em empresas start-up de alta tecnologia. Porto Alegre: Universidade Federal do Rio Grande do Sul, Programa de Pós-graduação em Administração, 2009. (Dissertação de mestrado).

DORNELAS, J. C. Empreendedorismo: transformando ideias em negócios. 3. Ed., Rio de Janeiro: Elsevier, p. 5-16, 2008.

ÉSTHER A. B., \& MELO, M. C. O. L. A construção da identidade gerencial dos gestores da alta administração de universidades federais em Minas Gerais. In. Cadernos EBAPE.BR, v. 6, n. 1, p. 1-17, 2008.

FIGUEIRA, K. K.; HORBE, T. A. N.; VARGAS, K. F. S.; MACHADO, E. C.; MOURA, G. L. Startups: estudo do processo de abertura e gerencialismo. In. Revista de Administração da Universidade Federal de Santa Maria, v. 10, edição especial, p. 56-71, ago. 2017.

FLEURY, A.; FLEURY, M. T. L. Estratégias empresariais e formação de competências. São Paulo: Atlas, 2001.

GIL, A. C. Como elaborar projetos de pesquisa. São Paulo: Atlas, 1996.

GODOY, A. S. Introdução à pesquisa qualitativa e suas possibilidades. In. Revista de Administração de Empresas. São Paulo: v. 35, n. 2, p. 57-63, abril 1995.

HERMANSON, B. O que é uma startup? São Paulo: Mundo Sebrae, 2011. 
HILL, L. Os novos gerentes: assumindo uma nova identidade. São Paulo: Makron Books, 1993.

HUNT, R.A. Entrepreneurial tweaking: an empirical study of technology diffusion through secondary inventions and design modifications by start-ups. In. European Journal of Innovation Management, v. 16, n. 2, p. 148-170, 2013.

LAKATOS, E. M.; MARCONI, M. A. de. Fundamentos de metodologia científica.São Paulo: Atlas, 2003.

LOPES, L. F. D.; FIGUERA, K. K.; BRESCIANI, S. A. T.; DAPPER, S. N.; MOURA, G. L. Competências gerenciais em startups tecnológicas brasileiras. In: 8th international symposium on technological innovation, 2017, Sergipe. Anais... Aracaju: ISTI, 2017.

MARRA, A. V.; MELO, M. C. O. L. A prática social de gerentes universitários em uma instituição pública. In. Revista de Administração Contemporânea, v. 9, n. 3, p. 9-31, 2005.

MINAYO, M. C. de S. O desafio do conhecimento: pesquisa qualitativa em saúde. São Paulo: Hucitec, 2004.

MINTZBERG, H. Trabalho do executivo: o folclore e o fato. São Paulo: Nova Cultural, 1986.

MOREIRA, A. M.; PIURCOSKY, F. P.; SILVA, S. V. JÚNIOR, E. S. G.; CALEGARIO, C. L. L. O perfil empreendedor: uma análise baseada em eventos de startups durante o ano de 2016 no sul de Minas Gerais. In. Revista Ciências Humanas, UNITAU, v. 10, n. Extra, ed. 19, p. 50-62, out. 2017.

MOTTA, P. R. Gestão contemporânea: a ciência e a arte de ser dirigente. Rio de Janeiro: Record, 1991.

NAGAMATSU, F. A; BARBOSA, J; REBECCHI, A. Business Model Generation e as contribuições na abertura de startups. In: II Simpósio Internacional de Gestão de Projetos - SINGEP e Simpósio Internacional de Inovação e Sustentabilidade, 2013, São Paulo. Anais... São Paulo: S2IS, 2013.

NOCETTI, A. A. N.; LAVARDA, C. E. F. As funções da controladoria desempenhadas nas empresas startups. In: $7^{\circ}$ congresso UFSC de controladoria e finanças e iniciação científica em contabilidade, 2017, Santa Catarina. Anais... Florianópolis: UFSC, 2017.

PAIVA, K. C. M.; COUTO, J. H. Qualidade de vida e estresse gerencial "pós-choque de gestão": o caso da Copasa-MG. In. Revista de Administração Pública, Rio de Janeiro, v. 42, n. 6, p. 1189-1211, Nov./Dez. 2008.

PICCHIAI, D. Competências gerenciais - caso de um hospital público. Fundação do desenvolvimento administrativo. São Paulo: 2003.

QUINN, R. E. et al. Competências gerenciais: princípios e aplicações. Rio de Janeiro: Elsevier, 2003.

RIES, E. A startup enxuta. São Paulo: Leya, 2012.

ROCHA, F. B. Proposta de modelo de geração de valor substancial e estratégia de crescimento acelerado em startups. São Paulo: Fundação Getúlio Vargas, Programa de Pós-Graduação em Administração, 2008. (Dissertação de mestrado).

RODRIGUES, A. C. A. L.; VILLARDI, B. Q. Formação do docente para a gestão universitária: uma análise indutiva dos professores gestores da pós-graduação strictu sensu da UFRRJ. In. Revista FOCO, v. 10, n. 2, jan./jul. 2017.

SCHUMPETER, J. A. A teoria do desenvolvimento econômico. São Paulo: Nova Cultural, 1988.

SOARES, A. C.; MELO, M. C. Desafios Gerenciais do terceiro setor de Belo Horizonte: Técnicos, políticos, críticos e praxeológicos. In. Revista de Gestão e Planejamento, Salvador, v. 10, n. 1, p. 38-52, jan./jun. 2009.

TRIVIÑOS, A. N. S. Introdução à pesquisa em ciências sociais: a pesquisa qualitativa em educação. São Paulo: Atlas, 1987.

VERGARA, S. C. Projetos e relatórios de pesquisa em administração. São Paulo: Atlas, 2009. 